\title{
Memórias da guerra: Um diálogo entre poemas de Odete Semedo e o registro fotográfico do conflito armado de 1998-1999, na Guiné-Bissau
}

\author{
Karina de Almeida Calado*
}

\begin{abstract}
Resumo
Este artigo analisa o testemunho poético da guerra da Guiné-Bissau, entre 1998 e 1999, a partir de poemas do livro No fundo do canto, de Odete Semedo, comparando-os com fotografias desse período histórico. Objetivase discutir a forma como essas duas linguagens, ao dialogarem entre si, "capturam" esse momento do país. Pretende-se demonstrar que, nos poemas, a voz poética assume-se como mensageira da nação, numa escrita que busca registrar o caos e expressar os horrores da guerra. A discussão é ancorada em estudos de Schøllhammer (2002; 2012), sobre o realismo afetivo; em Barthes (1984), que possibilita pensar como se manifestam, na escrita poética e na linguagem fotográfica, o efeito do "Isso foi" barthesiano; e nas reflexões de Huyssen (2000), sobre a paixão pela memória e como as práticas dessa memória podem trazer à tona "outras memórias".

Palavras-chave: Odete Semedo. Testemunho poético. Realismo. Memória.
\end{abstract}

As discussões sobre o realismo e a memória têm sido alvo de muitos estudos, no âmbito da literatura e das artes, de modo geral. Com base nesses estudos, podemos evidenciar que há uma preferência pelo realismo, na produção literária atual, tanto nas formas literárias quanto nos temas e conteúdos que agenciam uma experiência de leitura em contato com a realidade social, cultural e histórica. De igual forma, ancorados em Huyssen (2000), podemos afirmar que, em nenhum outro momento da nossa história, fomos tão obcecados pela memória quanto na sociedade atual.

Atualizando as discussões sobre a realidade, como referente da literatura e das artes, Foster (apud SCHØLLHAMMER, 2002, p. 76) propõe uma mudança na concepção da realidade, antes identificada como o efeito de representação, mas que, agora, passa a apontar para o real como evento de trauma. Segundo Schøllhammer,

* Pontifícia Universidade Católica de Minas Gerais - (PUC Minas). Doutoranda em Literaturas de língua portuguesa, pela PUC Minas, com bolsa Capes. Pesquisadora do Grupo de Estudos Comparados: Literatura, História e Interdisciplinaridade. Integrante do Projeto de Pesquisa Migrações e deslocamentos: a constituição de estéticas diaspóricas nas literaturas africanas de língua portuguesa. 
essa questão deve ser ainda mais ampla, compreendendo o realismo como uma combinação entre representação e não representação, capaz de "intervir na realidade receptiva e de agenciar experiências perceptivas, afetivas e performáticas que se tornem reais". (SCHØLLHAMMER, 2012, p. 130).

Essas questões iluminam a nossa análise acerca do testemunho poético escrito por Odete Costa Semedo sobre a guerra da Guiné-Bissau, ocorrida entre 1998 e 1999. Em seu cantopoema No fundo do canto, a poetisa busca encenar essa realidade histórica e agenciar o encontro do seu interlocutor com o evento traumático, por meio de efeitos sensíveis na linguagem poética. A autora lança mão de recursos que evocam as imagens da guerra, o que nos torna possível a comparação com o registro fotográfico do conflito. Essas duas linguagens "capturam" esse momento histórico do país e constituem-se práticas de memórias que ajudam a compor uma nova e mais completa história da Guiné-Bissau.

A vivência da guerra e os traumas consequentes tornam-se matéria-prima para a poesia de Odete Semedo. Em seu tecido poético, a autora se vale do olhar crítico e de sua sensibilidade de mulher e mãe para construir uma voz poética que se posiciona diante dos horrores da guerra, transformando o seu desabafo na tradução do sentimento de todos os filhos da Guiné-Bissau:

O livro mais triste que alguém haveria de ler na Guiné-Bissau. [...] o livro mais triste da Guiné-Bissau. [...] O espelho da dor de um povo e de tanto quantos se virem nele e através dele a silhueta do próprio destino. Deixarei que nele corram todas as lágrimas que não puderam ser choradas. As chagas mal saradas abrirei com o meu bisturi deixando correr todo o pus para que todos possam ver a real podridão e o verdadeiro fingimento. (SEMEDO, 2007, p. 13-14).

Consideramos que o cantopoema No fundo do canto é uma obra que se organiza a partir de fatos concretos da realidade do país. Ao buscar relatar o trauma de sua experiência na guerra, a voz poética recorre a "efeitos sensuais e afetivos parecidos ou idênticos aos encontros extremos e chocantes com os limites da realidade, em que o próprio sujeito é colocado em questão" (SCHØLLHAMMER, 2012, p. 133). Valendo-se do recurso da escrita de si mesma, essa voz tenta construir em sua poesia o equivalente sensível da sua experiência de contato com o real. Dessa forma, o interlocutor tem a possibilidade de tocar, ou de entrar em contato com o real, reagindo afetivamente diante dos efeitos sensíveis da experiência reproduzida.

Diante do cenário de destruição, do som dos disparos na cidade e da necessidade 
de partir e deixar tudo o que foi construído para trás, a voz poética busca compreender a realidade que transformou Bissau numa "cidade amaldiçoada", mas que "antes paraíso fora" (SEMEDO, 2007, p.77). Descortinando os véus de sua escrita, essa voz recorre ao exercício metalinguístico para manifestar a inexistência de gestos e palavras que possam expressar a sua dor, que é também a dor de todos de seu país:

Dores e desaires dos caminhantes

Que palavras

poderão espelhar este desaire?

$[\ldots]$

Ensinaram-me

que as letras

que as palavras traduzem

reproduzem

encantam

contam

pensamentos

intentos

devaneios

e sonhos

Para tanta aflição expressar

esta dor queimando

a minha alma

o nosso infortúnio

Este punhal...

cravado no meu chão

maldição de que deuses

para dilacerar

as entranhas da minha gente?

Como aplacar tanta

e tamanha dor

ninguém me desvendou

tal segredo.

(SEMEDO, 2007, p. 79-80)

Com base em Foster, Schøllhammer (2012) chama atenção para essa nova tendência nas artes, que busca reproduzir o choque causado pelo contato com o real, transformando a vivência artística na encenação da própria experiência, "em um nível de subjetividade mais profundo". Para ele, a interpelação sensual em produções artísticas dessa natureza encurta a distância entre arte e realidade. A arte 
propõe um encontro com a realidade em seu "aspecto mais cru, abrindo caminho, através de linguagens e imagens, através do simbólico e do imaginário, em direção a um encontro impossível com o real”. (SCHØLLHAMMER, 2012, p. 134).

O real está na obra, não apenas como algo definido ou representado, mas também sentido. Ele é a experiência impossível da Coisa em si. Tocados afetivamente, temos a possibilidade de experimentar uma sensação "próxima" da que o artista experimentou ao entrar em contato com o evento original e, desse modo, de encontrarmo-nos com o real. A mera existência e emergência do real produz angústia e trauma.

No poema acima, percebemos a encenação da incapacidade da voz poética de representar o seu contato com o trauma. Na leitura de versos como "Que palavras/ poderão espelhar este desaire?/ [...] Para tanta aflição expressar/ esta dor queimando/ a minha alma/ o nosso infortúnio/ Este punhal.../ cravado no meu chão", podemos ratificar que o real é indizível, indescritível, inarrável, incomunicável e informe. $\mathrm{O}$ artista busca sensações que se aproximem do real experienciado para agenciar a narrativa ou a encenação poética, mas nunca será tal qual o que foi vivido no evento original. A produção artística é mediada, portanto, na perspectiva de que o outro que receberá a obra sinta algo próximo da experiência original.

A manifestação da voz poética em No fundo do canto nos permite salientar que, embora o real seja inacessível à experiência, ele pode ser simbolizado de modo a provocar um efeito sensível do encontro com o trauma. Notamos que essa voz, ao enunciar nos primeiros versos do poema "Dores e desaires dos caminhantes": “Que palavras/ poderão espelhar este desaire?", sugere-nos que a tessitura de cada verso se faz em busca dessa simbolização do real.

$\mathrm{Na}$ experiência de leitura da obra, deparamo-nos com o agenciamento de duas realidades: a realidade que o texto representa e a realidade que o texto faz. $\mathrm{Na}$ primeira, referimo-nos ao contato do texto com a realidade histórica sobre a qual ele reflete. Na segunda, consideramos que o texto provoca sensivelmente o seu interlocutor, transformando a sua realidade. Diante da obra, o sujeito passa a reagir afetivamente com certa situação, coisa ou evento. A primeira realidade, que também podemos chamar de realidade externa, pode ser visualizada a partir da leitura dos versos do poema "A nossa rotina":

Tal como os baloberus anunciaram tal como os almamus

padres e pastores previram um dia 


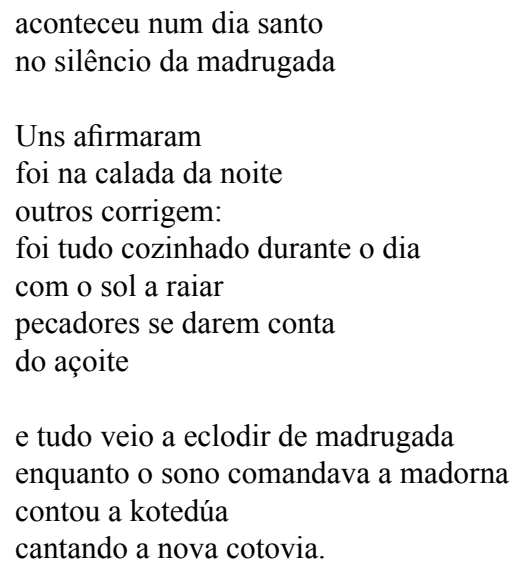

(SEMEDO, 2007, p. 66-67)

No poema "A nossa rotina", o sujeito poético sugere que a desgraça vaticinada por todos torna-se realidade. Ele encena o momento de eclosão do conflito armado e a forma como foi deflagrado. O conflito teve início com um golpe de estado, chefiado pelo general Ansumane Mané contra o presidente Nino Vieira, e se arrastou por 11 sangrentos meses. Durante o período, mais de $80 \%$ da população de Bissau deslocou-se para o interior do país, ou mesmo para o exterior, para fugir do conflito. Abandonada, Bissau teve muitos edifícios arrombados, saqueados, destruídos e incendiados. Essas marcas da presença da guerra no espaço da cidade tornam-se a matéria-prima do discurso poético.

Já a realidade que o texto faz opera no envolvimento sensível do sujeito, quebrando a fronteira entre realidade exposta e realidade envolvida esteticamente. Nela, os afetos agenciam a obra, manipulam sentidos e produzem outros afetos. Essa realidade converge com o conceito de "estética afetiva" proposto por Schøllhammer. Para ele, a estética afetiva se realiza por meio de "[...] singularidades afirmativas e criativas de subjetividades e intersubjetividades afetivas" (SCHØLLHAMMER, 2012, p. 138). Nessa perspectiva, a obra se torna real à medida que envolve sensivelmente o sujeito. Torna-se real em sua capacidade de agenciar experiências afetivas no encontro autor-obra-leitor. Essas considerações podem nos ser úteis na leitura do poema "As minhas lágrimas": 


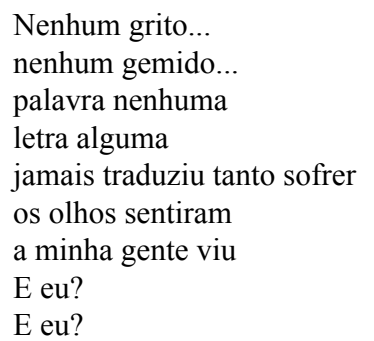

(SEMEDO, 2007, p. 81).

Os versos sugerem a angústia do eu poético diante dos horrores da guerra. Neles, a voz poética assinala, uma vez mais, a limitação da linguagem diante do evento extremo de dor e de sofrimento. Reconhece-se a ausência de signos capazes de traduzir, através da linguagem, as imagens sentidas apenas pelos olhos de quem vivenciou a guerra. Na leitura dos versos, somos levados a interagir sensivelmente com as imagens, inquietando-nos também com os questionamentos deixados pelo eu poético.

Encerrando o poema "As minhas lágrimas", os dois últimos versos encenam o questionamento do eu poético "E eu?/ E eu?" diante da sua própria condição de mãe, mulher, poeta, mensageira, de uma nação dilacerada pela guerra. Esse autoquestionamento é o ponto de partida para a intenção de testemunhar as suas vivências, que registram também as experiências vividas pelas pessoas de seu país.

Pela via do testemunho poético, a memória da guerra é evocada, promovendo uma compreensão sensível do passado e preenchendo lacunas na memória coletiva da Guiné-Bissau. O cantopoema constitui-se também num importante contributo para uma revisão da história oficial guineense, uma vez que registra memórias inconvenientes da guerra, expondo as marcas da violência. No fundo do canto evoca a memória do conflito, buscando vinculá-la à emocionalidade que ela implica e agenciando-a afetivamente aos seus interlocutores.

Considerando o cantopoema como uma prática de memória que "captura" o momento histórico da Guiné-Bissau, convém pensarmos num diálogo possível entre essa obra e as fotografias feitas durante a Guerra dos Onze Meses. Partimos da noção de que, tanto o texto quanto as imagens, compõem um acervo de memórias do conflito, pois, embora não representem o real, foram produzidos em contato com o referente. São elementos que remetem ao que aconteceu e que promovem o registro e a possibilidade de releituras do passado.

Para Barthes (1984), ao discorrer sobre o noema, a essência da fotografia, 
em A câmara clara, a memória da fotografia é inquestionável, uma vez que, diferentemente de outros sistemas de representação, não há fotografia sem a referência no mundo. A fotografia, para ele, é a captura de um instante, o resultado do contato direto com o referente, de tal modo que, o que vejo na fotografia, de fato, existiu, esteve lá. Em um dado momento do passado, "Isso foi”:

Chamo de 'referente fotográfico' não a coisa facultativamente real a que remete uma imagem ou signo, mas a coisa necessariamente real que foi colocada diante da objetiva, sem a qual não haveria fotografia. [...] na Fotografia jamais posso negar que a coisa esteve lá. Há dupla posição conjunta: de realidade e de passado. (BARTHES, 1984, 114-115 - destaques do autor).

Embora, para Barthes (1984), o contato com a realidade não faça parte da essência do texto poético, no caso da obra No fundo do canto, os poemas dialogam com as fotografias em torno do que ele chamou de studium: conteúdo histórico, social, cultural e ideológico comunicado pela foto. Texto e fotografia buscam "capturar" os momentos do país em guerra e testemunham os impactos do conflito na vida das pessoas e no cenário geográfico e social.

As considerações de Barthes sobre o noema da fotografia dialogam com os estudos de Susan Sontag (2003) sobre as fotografias de guerra. Para essa autora, tais fotografias nos impelem a perceber os "corpos lacerados de adultos e crianças. Mostram como a guerra despovoa, despedaça, separa, arrasa o mundo construído. [...] Olhem, dizem as fotos, é assim. É isto o que a guerra faz. E mais isso, também isso a guerra faz" (SONTAG, 2003, p. 12-14 - destaques da autora). Para quem está distante da guerra, ela se torna real ao ser registrada, especialmente, em fotografias. A fotografia tem o poder do choque imediato, é a marca do referente trazido para a câmera, por meio de alguém que esteve lá para tirá-la.

Os testemunhos poéticos e fotográficos são posicionamentos políticos e ideológicos contra a guerra. Constituem maneiras de seus autores expressarem sua desaprovação a todo tipo de violência e buscarem nos sensibilizar, despertandonos a consciência do sofrimento do outro. São atitudes que visam nos tirar da zona de conforto, da nossa indiferença cotidiana, para também renunciarmos à guerra. Sensibilizados, podemos perceber que os conflitos são evitáveis e injustificáveis e passamos a não aceitar o silêncio, a passividade. Incitam a reflexão sobre quem provocou e quem são os responsáveis pelo horror da guerra. Nesse sentido, cabe mencionarmos os versos do poema "Tanta súplica evocou os Irans": "Há 
culpados.../ Que não fiquem mudos/ nem impunes" (SEMEDO, 2007, p. 87), em que a voz poética nitidamente lança mão de um protesto de justiça aos que fazem a guerra. Como afirmou Sontag:

Mostrar um inferno não significa, está claro, dizer-nos sobre como retirar as pessoas do inferno, como amainar as chamas do inferno. Contudo, parece constituir um bem em si mesmo reconhecer, ampliar a consciência de quanto sofrimento causado pela crueldade humana existe no mundo que partilhamos com os outros. (SONTAG, 2003, p. 95).

Indo ao encontro das considerações de Nelly Richard (1999, p. 322), compreendemos que texto e fotografia são cenas de produção de linguagem que quebram com o silenciamento e o apagamento de registros impostos pelo sistema político e que abordam sensivelmente as memórias da guerra. Uma vez inscritas essas memórias, temos nelas a possibilidade de questionamento e reinterpretação do passado, podendo, inclusive, pensar um futuro diferente para a nação. Ratifica Richard: "imagens e palavras, formas e conceitos ajudam a trasladar a experiência ressignificada a planos de legibilidade em que a matéria do vivido fará parte de uma compreensão dos fatos capaz de desofuscar os nódulos da violência [...]" (RICHARD, 1999, p. 332). Essas memórias compõem temas sobre os quais podemos pensar a sociedade e asseguram que os crimes retratados continuem na lembrança da nação.

Para ilustrar os nossos argumentos, evocamos algumas cenas de produção de linguagem sobre o conflito que dialogam entre si. De maneira intercalada, apresentamos o testemunho poético narrado no poema "Mas o evidente era a odisseia" (SEMEDO, 2007, p. 77-78) e os testemunhos fotográficos de Adalberto Rosa (Agência Lusa) ${ }^{1}$ e do Padre João: ${ }^{2}$

$[\ldots]$

Homens mulheres e crianças todos tinham de partir o pensamento era deixar a cidade amaldiçoada que antes paraíso fora

1 A Agência Lusa cedeu gentilmente as fotografias para este trabalho. É proibida a reprodução ou publicação dessas imagens para outros fins.

2 Fotógrafo citado como autor das fotos disponíveis no blogue Escrita em Dia. 


\section{Foto $1^{3}$}

\section{Guine-Bissau unrest - Portugueses marine soldiers evacuate foreign people in a rescue operation during civil war in Guine-Bissau on 10th June 1998}

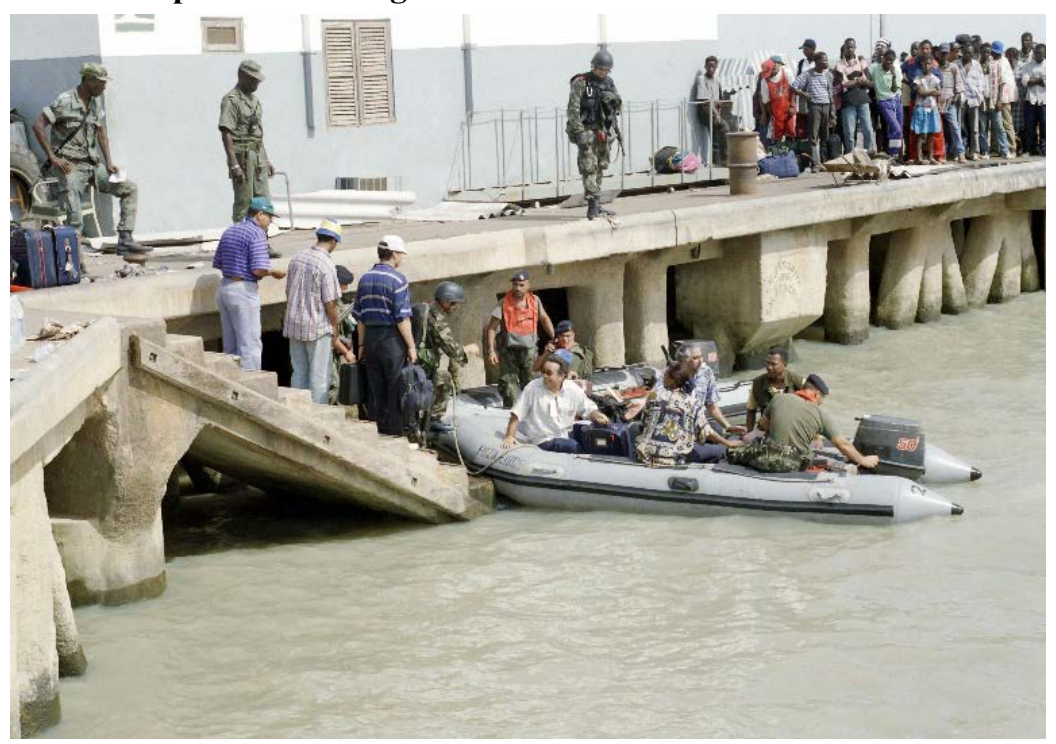

Fonte: Fotografia de Adalberto Rosa. Cedida pela LUSA - Agência de Notícias de Portugal, S.A., 2016.

O dia amanheceu prenhe de viagens

eram vários os grupos

que em fila indiana desfilavam

sem destino certo

Vais aonde?

Para onde os meus pés me levarem

E sei que será o mais longe possível

longe do cheiro e do fumo

da pólvora

3 Número de Documento: 6528670; Cidade, País: BISSAU, Guiné-Bissau; Data15/02/2007 16:12; Data de Evento: 10/06/1998 00:00; Gênero: Notícia; Copyright: (C) 2007 LUSA - Agência de Notícias de Portugal, S.A.; Fotógrafo: ADALBERTO ROSA; Tamanho original: 2500 x 1750; Nome do Objecto: GUINE-BISSAU UNREST; Ref. de Transmissão: AR09; Título: GUINE-BISSAU UNREST; Legenda: Portugueses marine soldiers evacuate foreign people in a rescue operation during civil war in Guine-Bissau on 10th June 1998. Temas: Agitação civil. É proibida a reprodução ou publicação dessa imagem para outros fins. 


\title{
Foto $2^{4}$
}

Guine-Bissau unrest - Guine-Bissau soldiers watch the documents of the refugees, in Bissau harbour, during civil war in Guine-Bissau on 10th June 1998

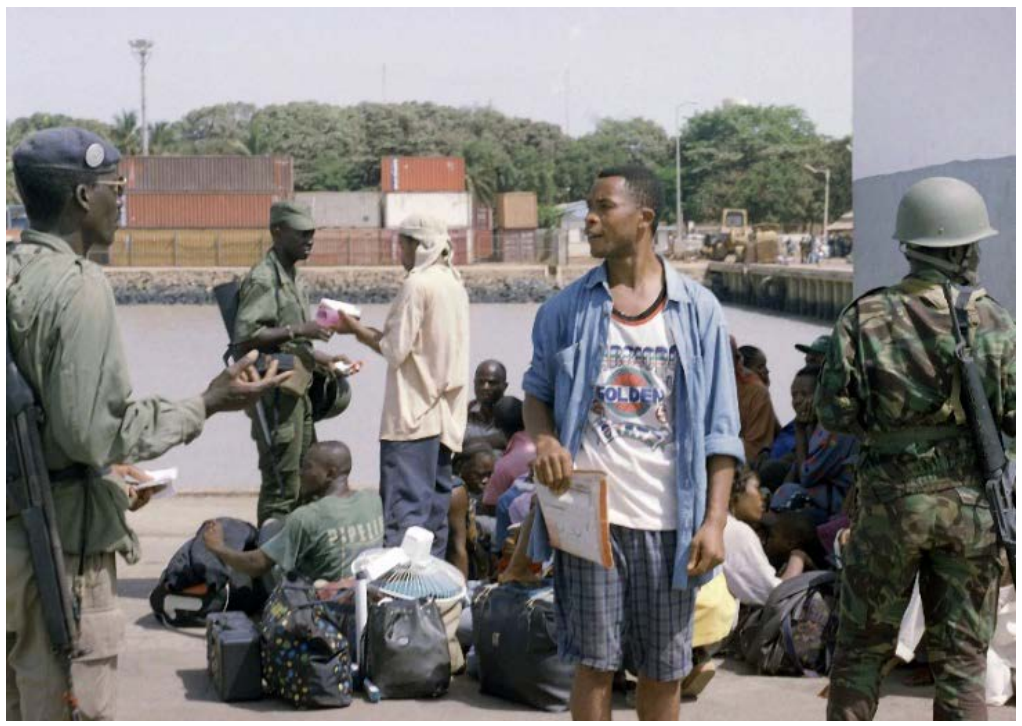

Fonte: Fotografia de Adalberto Rosa

Cedida pela LUSA - Agência de Notícias de Portugal, S.A., 2016

\author{
Muitos \\ não cumpriram todo o caminho \\ desfaleceram \\ Outros foram ficando para trás \\ mãos impotentes \\ olhar estático \\ Meu Deus \\ meus defuntos \\ castigo horroroso
}

4 Número de Documento: 6561901; Cidade, País: BISSAU, Guiné-Bissau; Data01/03/2007 15:43;
Data de Evento: 10/06/1998 00:00; Gênero: Notícia; Copyright: C 2007 LUSA - Agência de
Notícias de Portugal, S.A.; Crédito: LUSA; Fotógrafo: ADALBERTO ROSA; Tamanho original:
2500 x 1750; Nome do Objecto: GUINE-BISSAU UNREST; Ref. de Transmissão: AR10; Título:
GUINE-BISSAU UNREST; Legenda: Guine-Bissau soldiers watch the documents of the refugees,
in Bissau harbour, during civil war in Guine-Bissau on 10th June 1998. Temas: Agitação civil. É
proibida a reprodução ou publicação dessa imagem para outros fins. 
Foto $3^{5}$

\section{O último massacre}

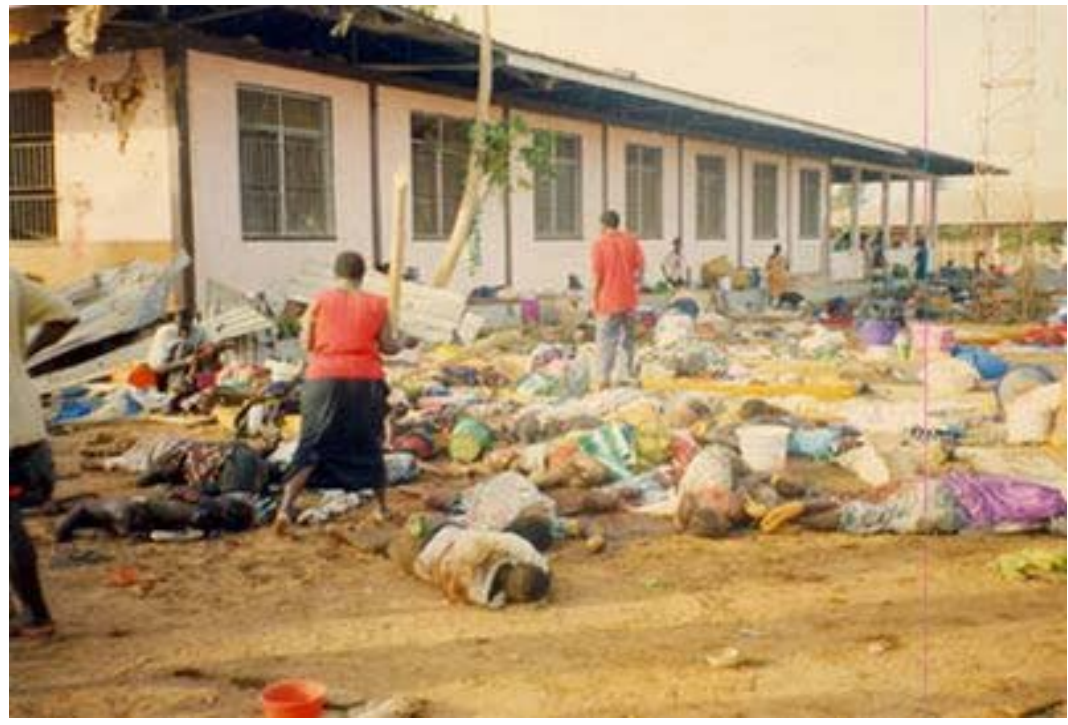

Fonte: Fotografia de Padre João Cedida pela LUSA

Agência de Notícias de Portugal, S.A., 2016

A sintonia entre os versos do poema e o conteúdo das fotografias parece completar as narrativas mutuamente. Fotografias não falam por si só. Poderíamos olhar para essas fotos e ter alguma noção de seu studium, mas necessitaríamos de narrativas verbais para sabermos, por exemplo, que se trata das consequências da Guerra da Guiné-Bissau, ocorrida entre 1998 e 1999. Assim, salientamos que as narrativas ampliam a nossa compreensão sobre o evento fotografado.

Poema e fotografia testemunham afetivamente o sentimento do "estar sem chão", o desolamento, a angústia de não ter para onde ir e, mesmo que se tenha, ter que abandonar tudo que fora construído. Texto e imagem evidenciam o êxodo, o deslocamento compulsório de massas humanas, expulsas de suas terras pelos interesses conflitantes daqueles que fazem a guerra.

Os testemunhos poéticos e fotográficos denunciam o caos, o cenário de destruição, o massacre de civis, que, sugerido pela última fotografia, mais parecem sacos de lixo do que propriamente o que são, seres humanos vitimados pela guerra.

5 Fotografia tirada por padre João, 1999. 1 fotografia; color. Está disponível em GUINÉ-BISSAU, 2013. 
Para Sontag, que faz reflexões em torno das ideias de Virginia Woolf sobre essa temática, "a escala do morticínio na guerra destrói aquilo que identifica as pessoas como indivíduos, e mesmo como seres humanos" (SONTAG, 2003, p. 54). O conteúdo dessa última fotografia revela o horror do último tiro dado na guerra, disparado em 7 de maio de 1999. De acordo com o blogue Escrita em Dia:

O último obus caiu no pátio de uma escola dos missionários do PIME. O local estava apinhado de populares, que ali se tinham refugiado do tiroteio nas ruas de Bissau. Aquela multidão de homens, mulheres e crianças ouviu o assobio do voo do obus, um som cada vez mais agudo. [...] Quarenta morreram logo no local. O depauperado Hospital Simão Mendes recebeu mais de 280 feridos. Muitos morreram aí nos dias seguintes, devido à gravidade dos ferimentos e à míngua de tratamento médico capaz de debelar infecções oportunistas. (GUINÉ-BISSAU, 2006).

Para finalizarmos este trabalho, consideramos que o cantopoema No fundo do canto e as fotografias do conflito resultam de memórias vividas que são inscritas na memória coletiva e, assim, tornam-se mais difíceis de serem esquecidas. Ratificamos que elas contribuem para a interpretação e reavaliação do passado nacional, ajudando a escrever a história de uma nova nação. Para Huyssen (2000, p. 34), esses testemunhos ajudam a "garantir um futuro da memória", pois representam a memória vivida, e esta, quando ativa, é "incorporada no social isto é, em indivíduos, famílias, grupos, nações e regiões. Estas são as memórias necessárias para construir futuros locais diferenciados num mundo global”. (HUYSSEN, 2000, 36-37).

\title{
Memories from the war: a dialog between poems by Odete Semedo and the photographic register from the 1998-1999 armed conflict in Guinea- Bissau
}

\begin{abstract}
This article analyzes the poetic testimony of the Guinea-Bissau war, between 1998 and 1999, based on poems from the book No fundo do canto, by Odete Semedo, comparing them with photographs from that historical period. Our objective is to discuss the way these two languages "capture" the country's moment. We intend to demonstrate that, in the poems, the poetic voice assumes itself as the nation's messenger, with a writing that registers
\end{abstract}


the chaos and expresses the horrors of war. The discussion is anchored on studies by Schøllhammer $(2002 ; 2012)$ about affective realism; by Barthes (1984), that makes it possible to think how they manifest themselves in poetic writing and in the photographic language, using the effect of the barthesian "This was"; and in the reflections by Huyssen (2000), about the passion for the memory and how the practices of that memory can bring forward "other memories".

Keywords: Odete Semedo. Poetic Testimony. Realism. Memory.

\section{Referências}

BARTHES, Roland. A câmara clara. Tradução de Júlio Castañon Guimarães. Rio de Janeiro: Nova Fronteira, 1984.

GUINÉ-BISSAU, a guerra civil: o último massacre. Escrita em dia. 2006. Disponível em $<$ http://blogda-se.blogspot.com.br/2006/06/guin-bissau-guerracivil-o-ltimo.html>. Acesso em: 24 jun. 2013.

HUYSSEN, Andreas. Passados presentes: mídia, política, amnésia. In: HUYSSEN, Andreas. Seduzidos pela memória. Tradução de Sérgio Alcides. Rio de Janeiro: Editora Aeroplano, 2000.

RICHARD, Nelly. Políticas da memória e técnicas de esquecimento. In: MIRANDA, Wander Melo (Org.). Narrativas da modernidade. Belo Horizonte: Editora UFMG, 1999. p. 321-338.

ROSA, Adalberto. Guine-Bissau Unrest. Lisboa, 2007. 2 fotografias, color., tamanho original $2500 \mathrm{~cm} \times 1750 \mathrm{~cm}$.

SEMEDO, Odete Costa. No fundo do canto. Belo Horizonte: Nandyala, 2007.

SCHØLLHAMMER, Karl Erik. À procura de um novo realismo - Teses sobre a realidade em texto e imagem hoje. In: OLINTO, Heidrun Krieger (Org.). Literatura e Mídia. São Paulo: Loyola, 2002. p. 76-90.

SCHØLLHAMMER, Karl Erik. Realismo afetivo: evocar realismo além da representação: Tendências hiper-realistas na arte e na literatura da atualidade. Estudos de literatura contemporânea, n. 39, jan./jun. 2012. p. 129-148.

SONTAG, Susan. Diante da dor dos outros. Tradução de Rubens Figueiredo. São Paulo: Companhia das Letras, 2003.

Recebido em 05/03/2016

Aceito: 05/09/2016 